\title{
Peningkatan Kapasitas Sekolah Berbasis Sistem Informasi Perangkat Pembelajaran Komunikasi Orangtua Murid di Jakarta
}

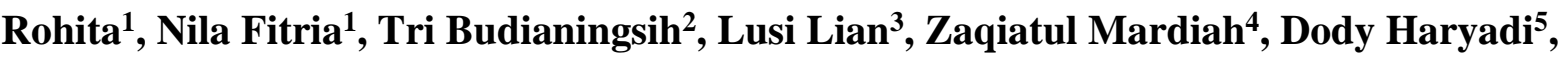 Yoedo Sambodho ${ }^{6}$}

\author{
${ }^{1}$ Program studi PG PAUD, Fakultas Psikologi dan Pendidikan, Universitas Al Azhar Indonesia \\ ${ }^{2}$ Bahasa dan Budaya Tiongkok, Fakultas Ilmu Pengetahuan Budaya, Universitas Al Azhar Indonesia \\ ${ }^{3}$ Bahasa dan Budaya Inggris, Fakultas Ilmu Pengetahuan Budaya, Universitas Al Azhar Indonesia \\ ${ }^{4}$ Bahasa dan Budaya Arab, Fakultas Ilmu Pengetahuan Budaya, Universitas Al Azhar Indonesia \\ ${ }^{5}$ Informatika, Fakultas Sains dan Teknologi, Universitas Al Azhar Indonesia \\ ${ }^{6}$ Ilmu Komunikasi, Fakultas Ilmu Sosial dan Ilmu Politik, Universitas Al Azhar Indonesia \\ Jl. Sisingamangaraja, Kebayoran Baru, Jakarta Selatan, kode pos 12110 \\ Email Penulis Korespodensi: rohita@uai.ac.id
}

\begin{abstract}
South Jakarta and Central Jakarta are two areas in DKI Jakarta that have collaborated with Al Azhar University Indonesia in implementing community service activities in the Sharing for Indonesia (S4I) program. This activity was carried out to assist the education sub-departments in the two areas in increasing school capacity for the knowledge and skills that teachers need to possess at the level of kindergarten, elementary, junior high, to high school/vocational school. The existence of the 19th pandemic that has occurred since the beginning of 2020 has had a considerable impact, especially on the educational aspect, where teachers must be able to improve the competence and teaching abilities of their students by utilizing technology in the distance learning model (PJJ), both online and externally. network (offline). Increased knowledge is also needed for parents to be able to accompany their children while studying at home while being able to survive in difficult times due to Covid 19. The solution that will be given is to increase school capacity through the use of the Information System for Learning Communications Devices for Parents (SIPPKOM). SIPPKOM is provided by using the methods of socialization, training, mentoring, as well as monitoring and evaluation. The targets of this community service activity are school principals, teachers, and parents from early childhood education levels, namely kindergarten, elementary, junior high, and high school and vocational schools in the South Jakarta and Central Jakarta areas. The presence of the participants was carried out in collaboration with tribal partners from the education office from the two regions. The results of the activity showed satisfaction and increased knowledge and skills for participants after participating in the activity and utilizing SIPPKOM on the features of consulting services and S4I activities. The conclusion of this activity is that SIPPKOM can increase the capacity of schools during the pandemic, to support the improvement of the knowledge and skills of teachers in these schools.
\end{abstract}

Keywords: School capacity, SIPPKOM, Sharing for Indonesia, consulting service

\begin{abstract}
Abstrak
Jakarta Selatan dan Jakarta Pusat adalah dua wilayah di DKI Jakarta yang telah bekerjasama dengan Universitas al Azhar Indonesia dalam pelaksanaan kegiatan pengabdian masyarakat pada program Sharing for Indonesia (S4I). Kegiatan ini dilaksanakan untuk membantu sudin pendidikan di kedua wilayah tersebut dalam peningkatan kapasitas sekolah akan pengetahuan dan keterampilan yang perlu dimiliki guru-guru baik di level TK, SD, SMP, hingga SMA/ SMK. Adanya pandemic 19 yang terjadi sejak awal tahun 2020 memberi dampak cukup besar terutama pada aspek pendidikan,
\end{abstract}


dimana guru harus dapat meningkatkan kompetensi dan kemampuan membelajarkan anak didiknya dengan memanfaatkan teknologi dalam model pembelajaran jarak jauh (PJJ), baik secara dalam jaringan (daring) maupun luar jaringan (luring). Peningkatan pengetahuan juga diperlukan bagi orangtua agar dapat mendampingi anak-anaknya selama belajar di rumah sekaligus dapat bertahan di masa sulit akibat Covid 19. Solusi yang akan diberikan adalah dengan meningkatkan kapasitas sekolah melalui pemanfaatan Sistem Informasi Perangkat Pembelajaran Komunikasi Orangtua Murid (SIPPKOM). SIPPKOM diberikan dengan mengunakan metode sosialisasi, pelatihan, pendampingan, serta monitoring dan evaluasi. Sasaran dari kegiatan pengabdian masyarakat ini adalah kepala sekolah, guru, serta orangtua dari level pendidikan anak usia dini, yaitu TK, SD, SMP, serta SMA dan SMK di wilayah Jakarta Selatan dan Jakarta Pusat. Kehadiran peserta tersebut dilakukan bekerjasama dengan mitra suku dinas pendidikan dari kedua wilayah tersebut. Hasil kegiatan menunjukkan adanya kepuasan serta peningkatan pengetahuan dan keterampilan bagi peserta setelah mengikuti kegiatan dan memanfaatkan SIPPKOM pada fitur layanan konsultasi dan kegiatan S4I. Simpulan dari kegiatan ini adalah SIPPKOM dapat meningkatkan kapasitas sekolah di masa pandemik, untuk mendukung peningkatan pengetahuan dan keterampilan guru-guru di sekolah tersebut.

Kata kunci: Kapasitas sekolah, SIPPKOM, sharing for Indonesia, layanan konsultasi

\section{PENDAhUluAN}

\section{Analisis Situasi}

Era digital merupakan suatu zaman yang ditandai dengan semakin canggihnya teknologi serta semakin banyaknya aspek kehidupan yang dipengaruhi oleh teknologi tersebut. Dampak digitalisasi itu sendiri juga terlihat dari beragamnya bentuk komunikasi untuk mendapatkan beragam informasi yang terjadi di masyarakat pada berbagai belahan dunia. Perlu ada upaya untuk bisa menyesuaikan diri dan berinteraksi dengan kondisi dan perubahan yang terjadi dengan sangat cepat.

Pendidikan menjadi satu aspek yang tidak hanya harus dapat menyesuaikan diri tetapi juga harus mampu menyiapkan berbagai kemungkinan yang akan terjadi baik sebagai dampak perubahan maupun tantangan yang akan mengiringinya. Berbagai permasalahan yang muncul dalam dunia pendidikan, mengharuskan adanya solusi yang cepat dan tepat. Karena, meskipun permasalahan lebih banyak dalam hal pembelajaran namun komponen lain dalam penyelenggaraan pembelajaran tersebut tidak sedikit. Permasalahan yang terjadi bukan hanya di desa tetapi juga di kota, seperti Jakarta.

Wilayah Jakarta khususnya Jakarta Selatan dan Jakarta Pusat, adalah dua wilayah yang menjadi sasaran dalam kegiatan pengabdian masyarakat. Hal ini selain dikarenakan lokasinya yang strategis dan dekat dengan kampus UAI, juga karena telah terjalin kerjasama antara ketiga instansi tersebut sejak tahun 2019 yang lalu. Lembaga pendidikan atau sekolah yang berada di kedua wilayah tersebut mencakup level TK, SD, SMP, dan SMA/SMK baik dengan status negeri maupun swasta. Kerjasama dilakukan diantaranya untuk meningkatkan berbagai kompetensi dari pendidik di kedua wilayah tersebut, khususnya kompetensi pedagogic dan kompetensi professional.

Namun, adanya pandemic Covid 19 upaya peningkatan kompetensi tentu perlu ditingkatkan, terlebih dengan adanya kebijakan belajar dari rumah. Dan, peningkatan kompetensi tidak hanya perlu dilakukan kepada guru, tetapi juga kepada orangtua yang mendapatkan peran lebih banyak dikarenakan keharusan memiliki kemampuan untuk dapat mendampingi anak-anaknya belajar di rumah.

Meskipun telah dilakukan upaya peningkatan, namun masih terdapat permasalahan lain yang juga membutuhkan sentuhan dari kedua belah pihak. Beberapa permasalahan yang dihadapi dalam dunia pendidikan, diantaranya, adalah terkait dengan metode pembelajaran, media pembelajaran, serta inovasi dalam model pembelajaran, termasuk penguasaan IT dan integrasinya dalam pembelajaran tersebut. Permasalahan yang terjadi tidak hanya pada level pendidikan anak usia dini dalam hal ini adalah pendidik TK, tetapi juga permasalahan dalam pembelajaran baik metode maupun media 
pembelajaran yang digunakan di SD, SMP, dan SMA/SMK.

Penguasaan IT masih menjadi pekerjaan rumah semua pihak yang bertanggungjawab terhadap pendidikan. Pengenalan IT perlu dilakukan sejak dini agar mereka memahami, terbiasa, dan dapat memanfaatkannya dengan benar dan meningkatkan keterampilan mereka di masa yang akan datang. Selain penguasaan IT, anak didik juga perlu diberikan kemampuan berkomunikasi secara efektif dan kreatif.

Untuk mengetahui lebih banyak permasalahan yang dialami oleh masyarakat kelompok pendidikan ini, di setiap penyelenggaraan S4I, diberikan kuesioner kepada peserta, baik guru maupun siswa. Hasil kuesioner menjadi bahan evaluasi dan pertimbangan dalam pelaksanaan kegiatan berikutnya. Sebagai bahan pertimbangan, diperoleh informasi mengenai materi-materi yang ingin didapatkan peserta yang ditujukan kepada dosen-dosen pelaksana S4I berdasarkan bidang studi, yang kemudian menjadi dasar dan pertimbangan pelaksanaan kegiatan kebutuhan peserta tersebut dapat terpenuhi.

\section{Permasalahan Mitra}

Dari informasi yang diberikan mitra, khususnya peserta kegiatan S4I, teridentifikasi permasalahan mitra sebagai berikut:

1. Perlunya pengembangan media pembelajaran yang dapat digunakan di luar kelas

2. Perlunya pemahaman dan kemampuan melaksanakan layanan PAUD HI pada satuan PAUD

3. Perlunya kemampuan memanfaatkan IT untuk pembelajaran

4. Perlunya penguasaan IT sejak dini

5. Perlunya pembentukan sikap kreatif dan adaptif bagi para siswa dalam menghadapi kampus merdeka

6. Perlunya peningkatan pengetahuan orangtua mengenai hukum, keuangan, pendidikan, keluarga, dan gizi.

\section{Solusi Permasalahan}

Pendidikan yang terselenggara di masa pandemi, tentu memberikan tantangan tersendiri bagi setiap pendidik pada semua level pendidikan, mulai TK hingga SMA/ SMK. Kolaborasi yang sangat kuat diperlukan tidak hanya di dalam sekolah tetapi juga dengan orangtua dan pemerintah daerah, dalam hal ini adalah suku dinas pendidikan di satu wilayah.

Universitas Al Azhar Indonesia (UAI) sebagai salah satu perguruan tinggi yang ada di masyarakat, memiliki peran dan tanggungjawab untuk memberikan kontribusi dalam dunia pendidikan. Upaya yang dilakukan adalah bermitra dengan suku dinas pendidikan di wilayah Jakarta Selatan, dimana lokasi UAI berada. Salah satu bentuk kerjasama yang dilakukan adalah melaksanakan program sharing for Indonesia.

Sharing for Indonesia adalah program pengabdian kepada masyarakat yang dirancang sebagai bentuk implementasi keilmuan para dosen UAI dalam merespon kebutuhan masyarakat, khususnya komunitas pendidikan. Program ini telah dilaksanakan sejak tahun 2012, dan penyelenggaraan telah dilakukan sebanyak 15 periode. Tujuan dilaksanakannya sharing for Indonesia adalah untuk: 1). Memotivasi dosen untuk melaksanakan kegiatan pengabdian masyarakat dalam bentuk sosialisasi, pelatihan, transfer ilmu pengetahuan dan teknologi (iptek), serta pendampingan, sehingga masyarakat dapat memanfaatkan hasil iptek tersebut, 2). Memanfaatkan dan menerapkan hasil-hasil iptek serta teknologi tepat guna (TTG) untuk pemberdayaan masyarakat, khususnya yang berada di lingkungan UAI, dan 3). Menyebarluaskan iptek yang didapat dari hasil penelitian (hilirisasi) untuk meningkatkan kualitas sumber daya manusia, kesejahteraan dan kemajuan masyarakat.

Berdasarkan permasalahan mitra yang telah teridentifikasi, maka solusi yang akan diberikan adalah dengan melaksanakan program sharing for Indonesia yang diintegrasikan ke dalam produk hasil penelitian sebagai upaya hilirisasi hasil penelitian berupa system informasi yang disebut system informasi perangkat pembelajaran - komunikasi orangtua murid atau yang disingkat dengan SIPPKOM.

Terdapat dua solusi yang dapat diberikan untuk mengatasi permasalahan yang ada, yaitu: pertama, sosialisasi, pelatihan, dan pendampingan yang sesuai dengan permasalahan yang dihadapi, dengan judul:

1. Biokonversi sampah organic dengan maggot black soldier fly (BSF) sebagai media pembelajaran di luar kelas dalam rangka implementasi MBKM,

2. Optimalisasi layanan PAUD HI pada satuan PAUD di masa Pandemi Covid 19, 
3. Pembuatan konten digital podcast cerita rakyat berbasis lintas budaya Indonesia Asia Timur (Jepang dan Tiongkok) sebagai bentuk kegiatan kelas merdeka belajar,

4. Implementasi Aplikasi Akuntansi Jurnal.ID

5. Coding for Kids,

6. Meningkatkan kemampuan komunikasi siswa agar adaptif dan kreatif menghadapi tantangan kampus merdeka,

7. Hukum zakat dalam perspektif perundangundangan

Kedua, memberikan layanan konseling agar permasalahan yang belum dapat terpecahkan melalui sosialisasi, pelatihan dan pendampingan dapat teratasi. Layanan konsultasi yang diberikan, mencakup: konsultasi gizi, konsultasi ketahanan keluarga, konsultasi pengelolaan keuangan keluarga, dan konsultasi hukum. Kedua bentuk solusi tersebut bisa didapatkan dengan mengakses SIPPKOM.

\section{METODE PELAKSANAAN}

Kegiatan pengabdian masyarakat ini dilakukan berkolaborasi antara universitas $\mathrm{Al}$ Azhar Indonesia dengan suku dinas pendidikan wilayah Jakarta Selatan dan Jakarta Pusat, serta kolaborasi antara 8 prodi di UAI. Berikut digambarkan bentuk kolaborasi antara UAI Sudin - Prodi serta bentuk integrasi SIPPKOM dengan program S4I.

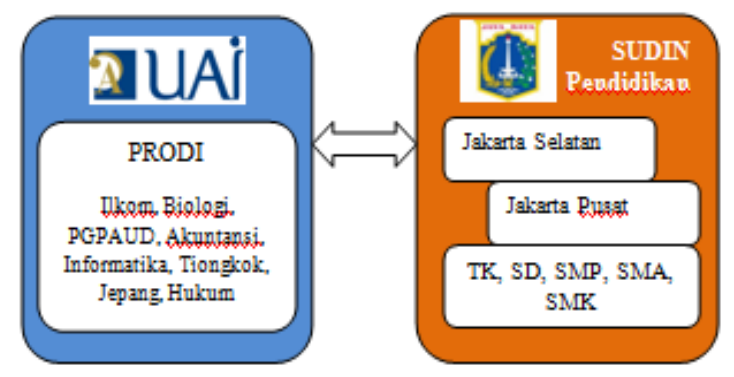

Gambar 1. Kolaborasi pelaksana abdimas dengan mitra kegiatan

Upaya melaksanakan kolaborasi diawali dengan melakukan komunikasi dan koordinasi dengan prodi-prodi yang menyatakan bersedia untuk terlibat dalam kegiatan pengabdian masyarakat. Beberapa hal yang dikoordinasikan adalah waktu dan tempat penyelenggaraan kegiatan. Hasil komunikasi dengan prodi, ditindaklanjuti dengan melakukan komunikasi kepada sudin di wilayah Jakarta Selatan dan Jakarta Pusat terkait kesediaan menjadi mitra dalam kegiatan pengabdian masyarakat ini. Dilanjutkan dengan pengajuan surat permohonan menghadirkan peserta kegiatan, serta pemberian surat undangan untuk hadir pada pelaksanaan kegiatan setelah diketahui dengan pasti waktu pelaksanaan dari setiap program studi.

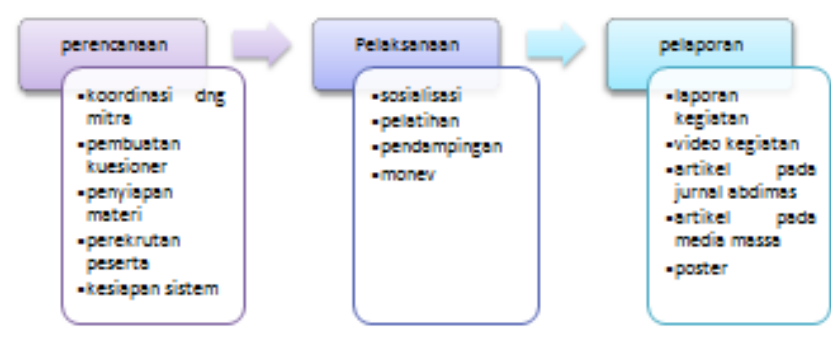

Gambar 2. Tahapan pelaksanaan kegiatan

Koordinasi dengan mitra juga dilakukan terutama untuk melihat kembali system informasi yang akan digunakan dan pengintegrasiannya dengan kegiatan sharing for Indonesia (S4I). Berikut digambarkan bentuk integrasi SIPPKOM dengan S4I.

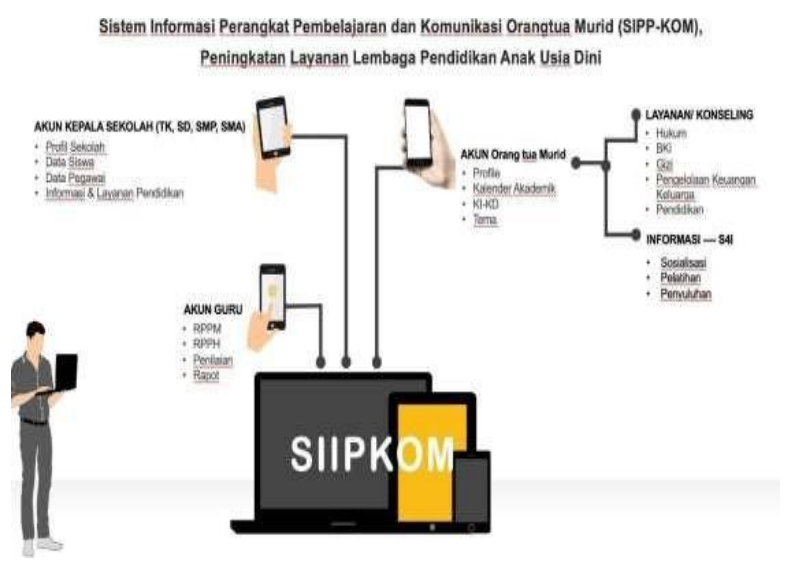

Gambar 3. Integrasi SIPPKOM dengan program S4I

Kegiatan pengabdian masyarakat ini akan dilakukan dengan 4 metode, yaitu sosialisasi, pelatihan, pendampingan, serta monitoring dan evaluasi.

\section{Waktu dan Tempat Pelaksanaan}

\section{Waktu}

Kegiatan sosialisasi, pelatihan dan pendampingan, serta monitoring dan evaluasi penggunaan SIPPKOM sebagai media digital sharing for Indonesia dilaksanakan dalam waktu 2 minggu, dimulai sejak Kamis, 16 Desember 2021 hingga Kamis, 23 Desember 2021. 
Kegiatan dilaksanakan dengan menghadirkan peserta dari level pendidikan anak usia dini, sekolah dasar, sekolah menengah pertama, hingga sekolah menengah atas dan menengah kejuruan, meliputi kepala sekolah, guru dan atau operator, serta orangtua dari masing-masing level pendidikan tersebut. Total jumlah peserta sebanyak 55 orang

\section{Tempat pelaksanaan}

Kegiatan pengabdian masyarakat dilaksanakan secara dalam jaringan (daring) maupun luar jaringan (luring). Kegiatan secara daring dilaksanakan dengan menggunakan aplikasi virtual zoom meeting. Sementara kegiatan secara luring dilaksanakan di Universitas Al Azhar Indonesia.

Terdapat sembilan (9) kegiatan pengabdian kepada masyarakat yang dilaksanakanoleh sembilan (9) tim secara daring, yaitu: tim dari prodi PGPAUD, tim dari prodi bahasa dan budaya Tiongkok, tim dari prodi bahasa dan budaya Jepang, tim dari prodi Informatika, tim dari prodi Akuntansi, tim dari prodi Ilmu Komunikasi, tim dari prodi Hukum, tim dari prodi Biologi, dan dan tim gabungan dari prodi bahasa dan budaya Tiongkok, prodi bahasa dan budaya Inggris, prodi bahasa dan budaya Arab, prodi Informatika, prodi Ilmu Komunikasi, serta prodi PGPAUD.

Adapun pelaksanaan kegiatan luring dilakukan oleh prodi PGPAUD yang dilaksanakan di kator walikota Jakarta Pusat wilayah 1, Prodi Ilmu Komunikasi yang dilaksanakan di ruang Amphiteater Universitas Al Azhar Indoensia, serta tim gabungan prodi yang dilaksanakan di ruang auditorium Arifin Panigoro Universitas Al Azhar Indonesia.

\section{Alat dan Bahan:}

Alat yang digunakan dalam kegiatan ini adalah:

1. Laptop

2. Kandang untuk pembiakan/ budidaya maggot

Sementara bahan yang digunakan, adalah:

1. System informasi yang berisi konten layanan konsultasi serta informasi pelaksanaan kegiatan sharing for Indonesia yang dilaksanakan prodi.

2. Cerita berbasis lintas budaya IndonesiaAsia Timur (budaya Tiongkok dan Jepang)

3. Maggot Black Soldier Fly (BSF)

4. Aplikasi Akuntansi Jurnal.Id

5. Aplikasi Kartu Tumbuh Kembang Anak
6. Tools online "Scratch"

7. Materi tentang Zakat dan Undangundangnya

\section{Langkah Pelaksanaan}

Kegiatan dilaksanakan dalam bentuk luring maupun daring mencakup sosialisasi, pelatihanpendampingan, serta monitoring dan evaluasi. Berikut dipaparkan langkah pelaksanaan metode kegiatan tersebut.

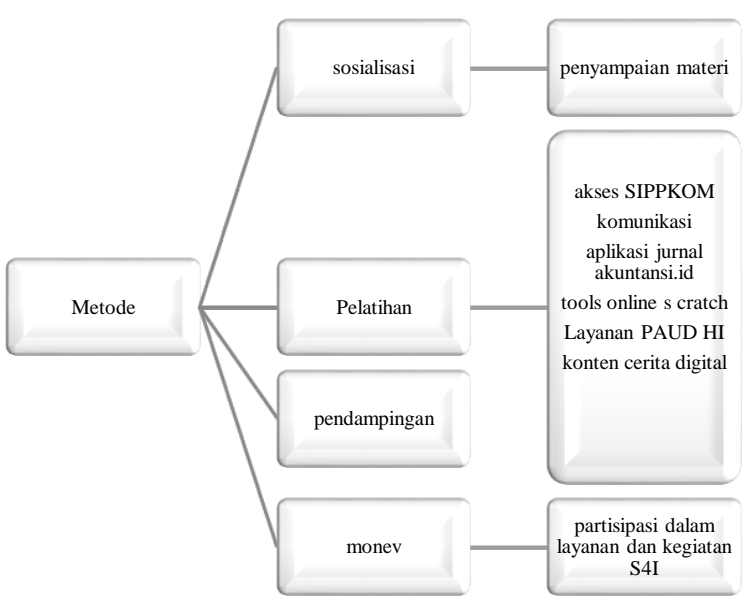

Gambar 4. Langkah pelaksanaan

\section{HASIL DAN PEMBAHASAN}

\section{Sosialisasi}

Kegiatan sosialisasi dilakukan dalam bentuk daring menggunakan virtual zoom, dengan menghadirkan rektor Universitas Al Azhar Indonesia untuk memberi sambutan sekaligus membuka kegiatan pengabdian masyarakat dengan judul SIPPKOM: Media Digital Sharing for Indonesia. Kegiatan dilakukan pada Kamis, 16 Desember 2021. Sambutan diberikan pula oleh kepala suku dinas pendidikan Jakarta Pusat wilayah 2, Ibu Dr. Hj. Uripasih, M.Pd. Dalam kesempatan tersebut beliau menyatakan menyambut hangat kegiatan pelatihan dan pendampingan yang akan diberikan kepada kepala sekolah, guru, dan orangtua dari mulai tingkat TK, SD, SMP, dan SMA-SMK.

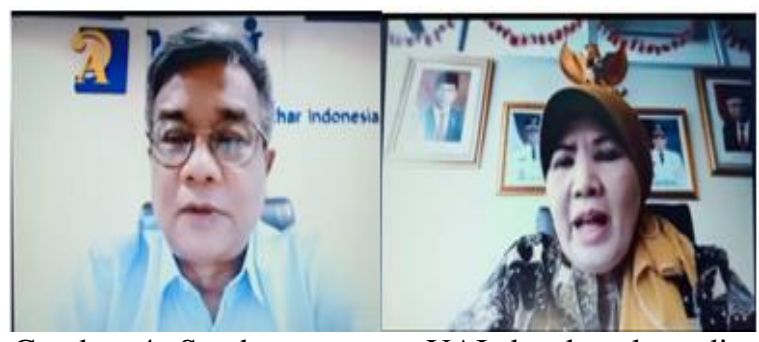

Gambar 4. Sambutan rector UAI dan kepala sudin 
pendidikan wilayah 2 Jakarta Pusat dalam kegiatan webinar sosialisasi SIPPKOM: Media Digital S4I

Kegiatan dilanjutkan dengan pemaparan materi mengenai SIPPKOM dan layanan yang tersedia di dalamnya. Pemaparan disampaikan oleh tim pelaksana abdimas Bapak Dody Haryadi, M.Ti., dan ibu Nila Fitria, M.Pd.

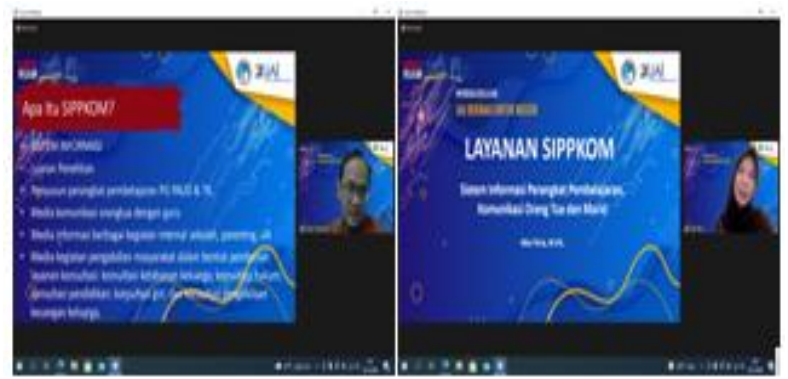

Gambar 5. Pemaparan materi SIPPKOM dan layanan

Di waktu yang bersamaan dilaksanakan pula kegiatan sharing for Indonesia oleh tim dari prodi PGPAUD, yang bermitra dengan suku dinas pendidikan wilayah 1 Jakarta Pusat. Acara dibuka oleh kaprodi PPGPAUD UAI, ibu Nila Fitria, M.Pd., dilanjutkan sambutan yang disampaikan kepala seksi PAUD dan Dikmas, ibu Wiji Kusrini, M.Pd.

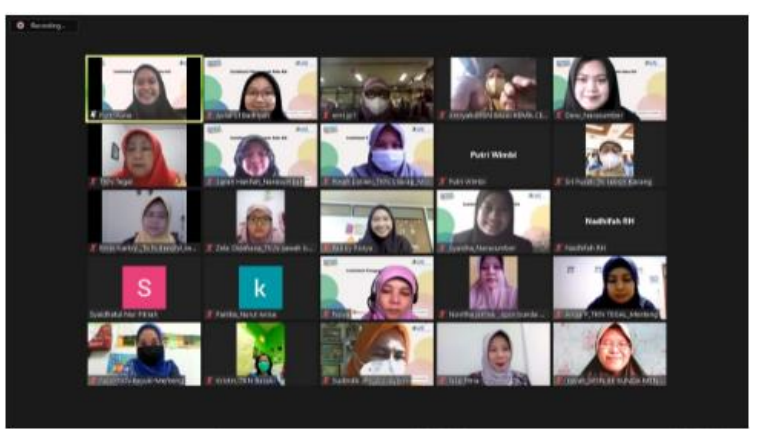

Gambar 6. Webinar sosialisasi layanan PAUD Holistik Integratif

Kegiatan pengabdian masyarakat yang dilaksanakan oleh prodi PGPAUD ini menyasar guru-guru PAUD untuk dapat menggunakan aplikasi kartu ibu dan anak mobile (mKIA), secara daring, khususnya di Kecamatan Tanah Abang, wilayah 1 Jakarta Pusat.

\section{Pelatihan-pendampingan}

Kegiatan pengabdian kepada masyarakat berlanjut di hari Jumat, 17 Desember 2021 melalui kegiatan pelatihan dan pendampingan. Kegiatan berlangsung di ruang auditorium
Arifin Panigoro Universitas Al Azhar Indonesia mulai pukul $08.00-11.30 \mathrm{WIB}$.

Diawali dengan laporan ketua pelaksana, ibu Rohita, M.Pd., mengenai tujuan kegiatan serta jumlah peserta, kemudian sambutan sekaligus membuka acara oleh wakil rektor 1 UAI bapak Dr. Zirmansyah, dilanjutkan dengan sambutan dari kepala seksi pendidikan menengah wilayah 1 dan 2 Jakarta Selatan, bapak Sony Juhersoni serta bapak Sarwoko.
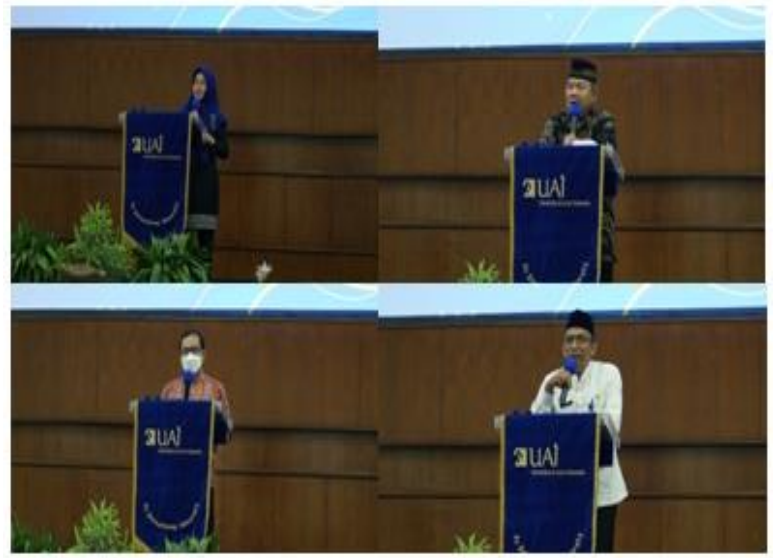

Gambar 7. Pembukaan dan sambutan

Kegiatan dilanjutkan dengan pemaparan singkat mengenai fitur-fitur yang terdapat dalam SIPPKOM yang disampaikan oleh bapak Dody Haryadi, M.Ti.

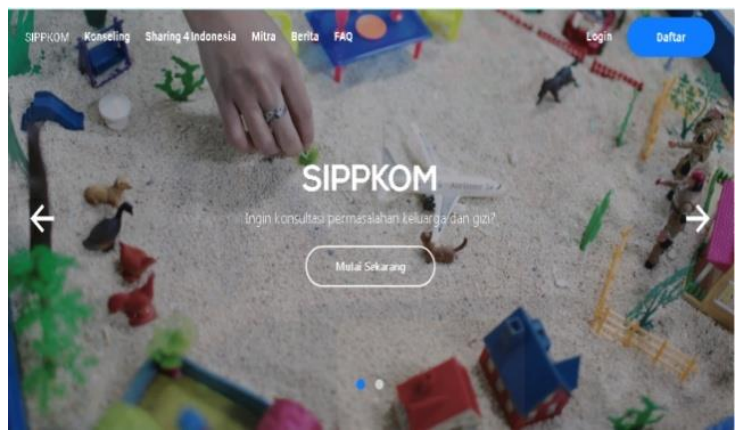

Gambar 8. Tampilan awal SIPPKOM 


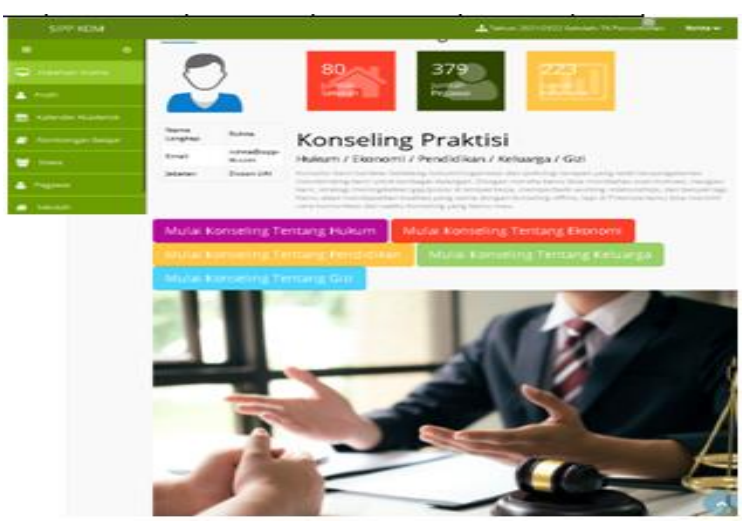

Gambar 9. Tampilan konten SIPPKOM- Layanan konseling

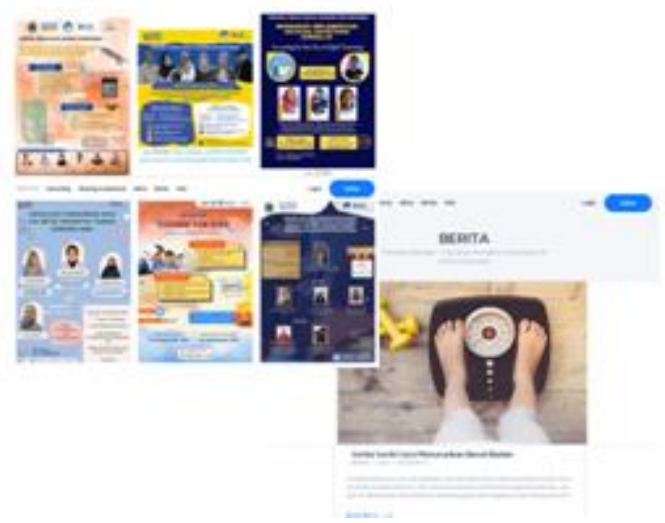

Gambar 10. Tampilan informasi S4I dan berita

Kegiatan dilanjutkan dengan pelatihan serta pendampingan menggunakan SIPPKOM bagi seluruh peserta yang terdiri dari orangtua, guru, dan kepala sekolah dari TK, SD, SMP, SMA, dan SMK. Diawali dengan melatih kepala sekolah untuk menginput data atau identitas lembaganya, hingga kemudian memberi akses kepada guru dan orangtua yang telah didaftarkan dalam system tersebut.
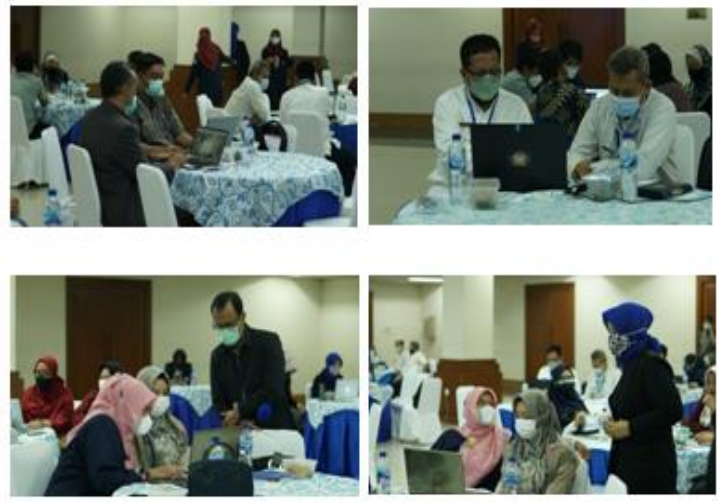

Gambar 11. Pelatihan dan pendampingan

Selain pelatihan dan pendampingan penggunaan SIPPKOM, juga dilaksanakan kegiatan pengabdian masyarakat lain seperti pelatihan coding for kids, pelatihan layanan PAUD Holistik Integratif, pelatihan aplikasi akuntansi jurnal. ID, serta pelatihan komunikasi efektif.

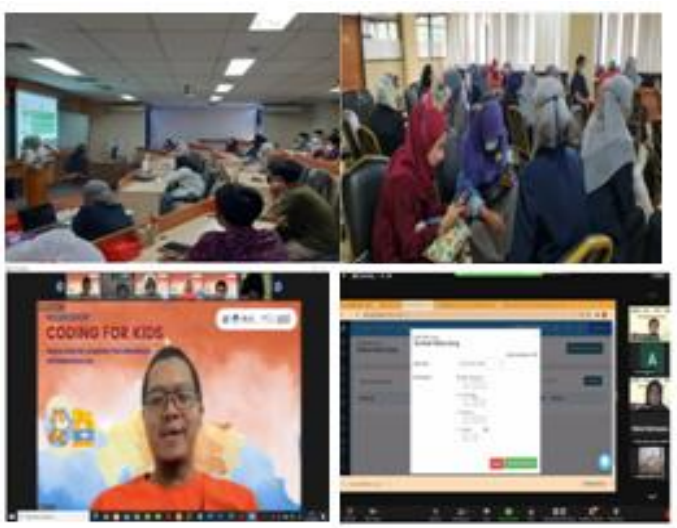

Gambar 12. pelatihan komunikasi (kiri atas), pelatihan penggunaan KIA mobile (kanan atas), pelatihan coding for kids (kiri bawah), pelatihan jurnal.ID (kanan bawah)

\section{Monitoring dan evaluasi}

Kegiatan monitoring dan evaluasi dilakukan dengan melihat aktivitas di dalam SIPPKOM, yaitu pada bagian penggunaan layanan konsultasi, berita, serta kegiatan sharing for Indonesia.

Pada bagian layanan konsultasi, terlihat melalui menu chating yang berisikan percakapan antara konselor dengan konselee. Pada bagian ini juga akan terlihat siapa saja yang pernah melakukan konsultasi pada layanan tertentu.

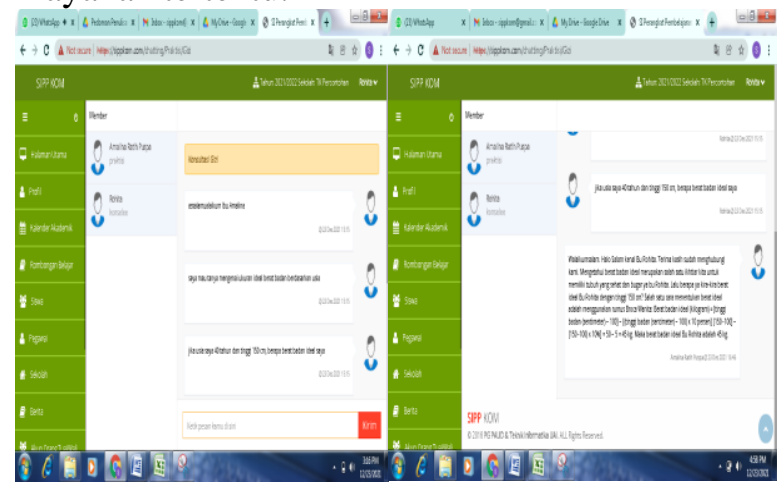

Gambar 13. Interaksi dalam layanan konsultasi gizi 


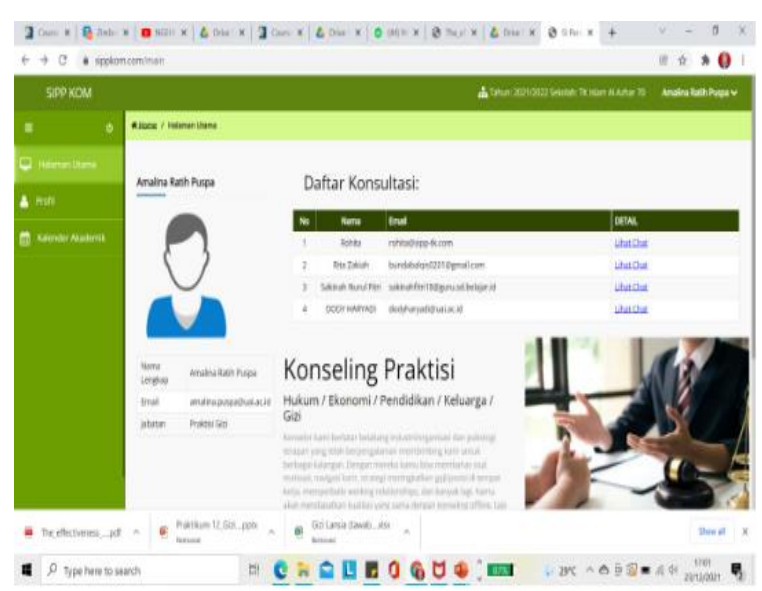

Gambar 14. Tampilan jumlah pengguna layanan konsultasi

Monitoring juga dilakukan dengan melihat fitur BERITA untuk mengetahui adakah pembaca yang membuat tulisan dan mempublikasikannya melalui SIPPKOM.

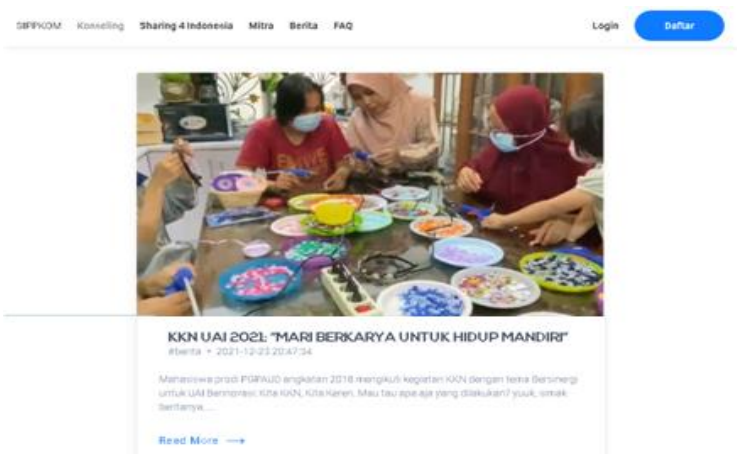

Gambar 15. Tampilan berita mengenai kegiatan KKN mahasiswa

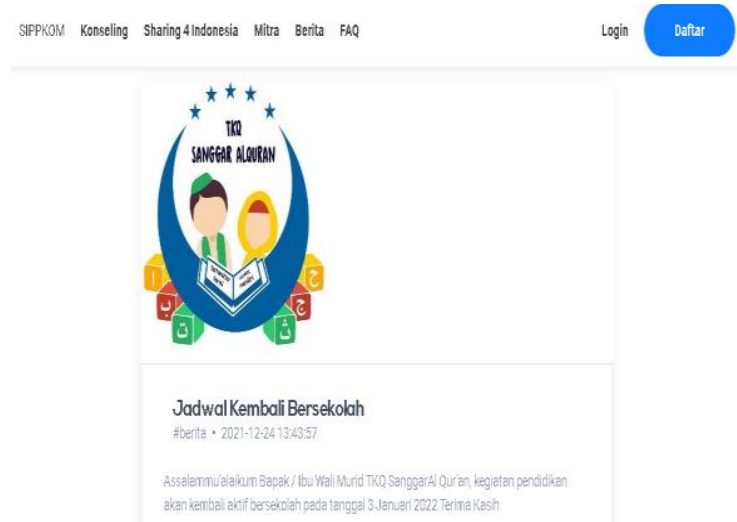

Gambar 16. Tampilan berita dari peserta kegiatan

Selain itu, monitoring juga dilakukan dengan melihat fitur sharing for Indonesia untuk mengetahui ada tidaknya pengguna SIPPKOM yang melihat dan mengikuti kegiatan sharing for Indonesia yang dilaksanakan dosen dari prodi di UAI. Akses langsung dapat digunakan calon peserta dengan mengklik link zoom yang tercantum dibagian bawah poster prodi pelaksana.

Kegiatan pengabdian masyarakat yang telah dilakukan memberikan informasi mengenai dampak dari pelaksanaan kegiatan ini. Berikut disajikan dalam bentuk grafik.

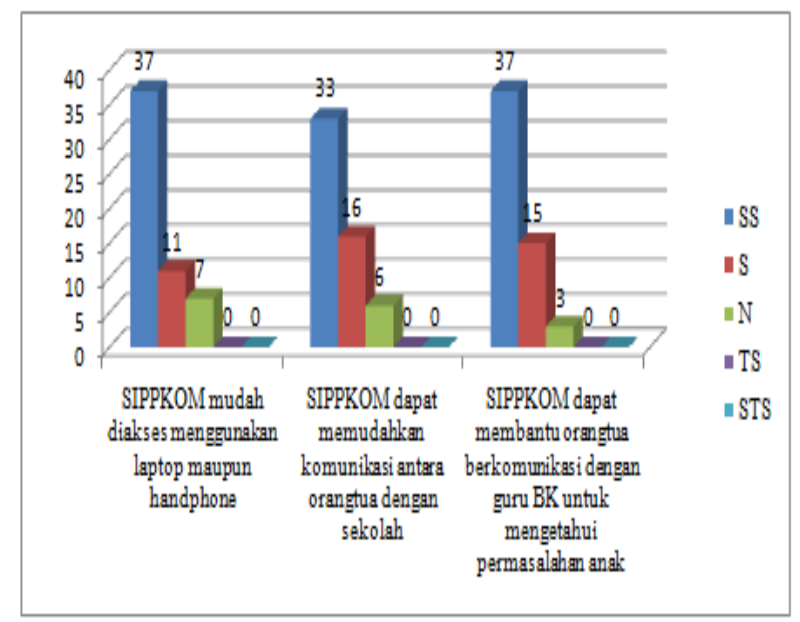

Gambar 17. Kemudahan akses SIPPKOM

Berdasarkan gambar 17 terlihat sebanyak 37 responden menyatakan bahwa SIPPKOM mudah diakses menggunakan laptop maupun handphone. Kemudahan yang didapat karena system informasi yang dibuat menggunakan metode System Develop Live Cycle (SDLC), dan dalam membuat perancangan menggunakan Unified Modelling Language (UML). UML adalah bahasa untuk spesifikasi, visualisasi, pembangunan dan dokumentasi system perangkat lunak (Abdurohman, et.al., 2012). SIPKOM dikembangkan dengan menggunakan bahasa pemrograman PHP (HyperText Preprocessor), dengan framework codelgniter. PHP adalah skrip bersifat server side yang ditambahkan ke dalam HTML, dimana system kerjanya diawali dengan permintaan yang berasal dari halaman website oleh browser (Kustiyaningsih, 2011).

Berdasarkan gambar 16 pula terlihat bahwa SIPPKOM dapat memudahkan komunikasi antara orangtua dengan sekolah. Selama masa pandemik ini, komunikasi yang terjalin lebih banyak menggunakan media whatsapp. dibandingkan media sosial, whatsapp menjadi media untuk pembelajaran online yang paling banyak digunakan sekaligus sebagai sarana penghubung guru dengan orang tua siswa (Kresnamurti, Fauziyah, Syafrida, 2021). Dipergunakannya whatsapp sebagai media komunikasi dikarenakan tersedianya berbagai fitur sangat membantu dalam system 
pembelajaran yaitu pengiriman video, foto, perekam suara, pengiriman file, dan juga video call group (Riadil, Nuraeni, prakoso, 2020).

$$
\text { SIPPKOM memang belum dapat }
$$
menggantikan whatsapp dan mungkin keberadaannya memang tidak untuk menggantikan whatsapp. Tetapi SIPPKOM dapat juga menjadi alternative media komunikasi antara orangtua dengan sekolah, yang tidak hanya mengetahui permasalahan anak-anaknya di sekolah tetapi orangtua juga dapat menambah informasi, pengetahuan dan keterampilan, bahkan membantu orangtua mendapatkan layanan konsultasi sesuai permasalahan yang dihadapi.

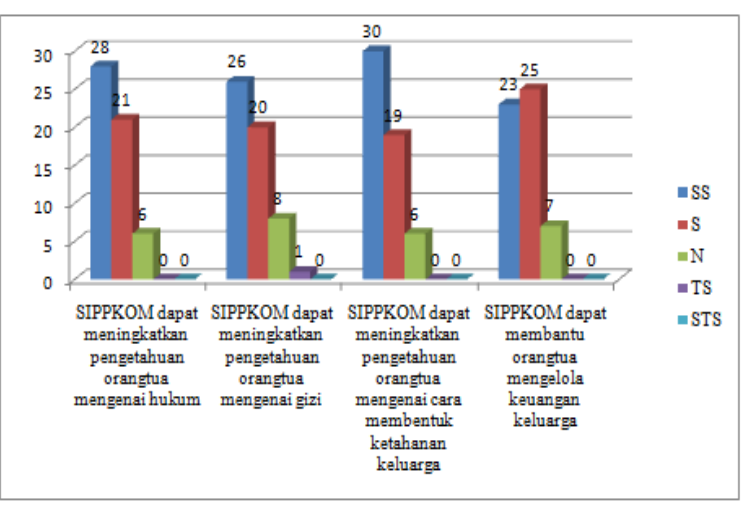

Gambar 18. Manfaat SIPPKOM bagi pengguna

Pada gambar 18 menunjukkan informasi bahwa layanan konsultasi yang tersedia di dalam SIPPKOM, yaitu layanan konsultasi Hukum, konsultasi gizi, konsultasi ketahanan keluarga, dan konsultasi pengelolaan keuangan keluarga dapat meningkatkan pengetahuan pengguna. Melalui layanan ini, orangtua maupun guru dapat bertanya terkait masalah yang dihadapi kepada konselor secara langsung. Adanya komunikasi langsung lebih memungkinkan bagi pengguna untuk memahami apa yang disarankan konselor untuk dilakukan sehingga masalah yang dihadapi dapat terselesaikan. Komunikasi langsung juga menjadi satu upaya agar pengguna dapat secara leluasa menyampaikan keluhan dan permasalahan yang dihadapi tanpa perlu menunggu waktu yang lama ataupun terganggu oleh hal-hal lainnya.

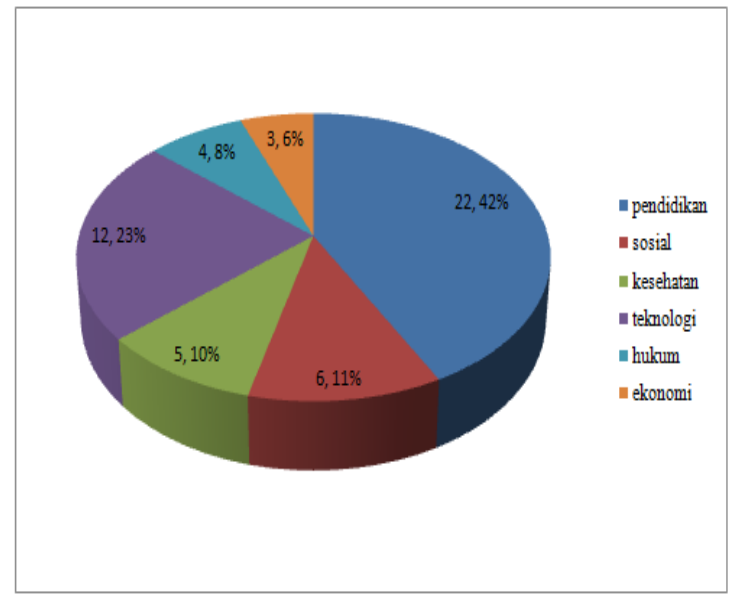

Gambar 19. Manfaat SIPPKOM pada bidang lainnya

SIPPKOM merupakan satu solusi yang diberikan kepada masyarakat dunia pendidikan yang diintegrasikan dengan program Sharing for Indonesia. Sebagai sebuah solusi, SIPPKOM memiliki dampak pada aspek kehidupan lainnya. Gambar 18. menunjukkan bagaimana SIPPKOM dapat memberi dampak pada bidang lain, meskipun sebagian besar yaitu $42 \%$ dampaknya masih pada bidang pendidikan.

Dampak lain yang dirasakan dari keberadaan SIPPKOM pada bidang kesehatan diantaranya didapatkan melalui penggunaan layanan konsultasi gizi. Untuk dampat pada bidang hukum, selain didapatkan dari penggunaan layanan hukum juga dikarenakan mengikuti kegiatan sharing for Indonesia yang dilaksanakan prodi hukum mengenai hukum zakat dalam perspektif perundang-undangan.

Adapun dampak dari sisi ekonomi selain didapat dengan menggunakan layanan konsultasi pengelolaan keuangan keluarga, juga diperoleh dengan mengikuti kegiatan sharing for Indonesia yang dilaksanakan prodi akuntansi mengenai penggunaan aplikasi akuntansi jurnal.ID.

Mengingat berbagai manfaat yang dapat diperoleh pengguna, dalam hal ini adalah lembaga sekolah mulai dari level TK, SD, SMP, hingga SMA-SMK, maka pengguna bersedia untuk menggunakan SIPPKOM sebagai media komunikasi di sekolah. 


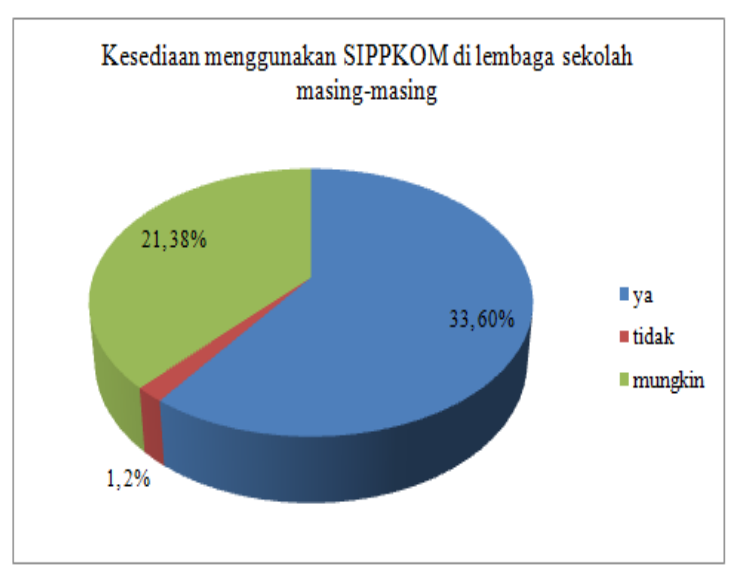

Gambar 20. Kesediaan menggunakan SIPPKOM

Berdasarkan gambar 20 terlihat bahwa $60 \%$ atau 30 peserta menyatakan bersedia menggunakan SIPPKOM, 38\% atau 21 peserta menyatakan mungkin akan menggunakan. Dan, 1 orang atau $2 \%$ menyatakan tidak akan menggunakan SIPPKOM di lembaganya. Hal ini dapat menjadi isyarat bahwa SIPPKOM dapat diterima di masyarakat khususnya dunia pendidikan karena pengguna dapat merasakan dan mengambil manfaat dari keberadaan SIPPKOM tersebut.

\section{SIMPULAN DAN SARAN}

Simpulan dari kegiatan pengabdian kepada masyarakat yang telah dilakukan ini adalah bahwa:

1. SIPPKOM dapat meningkatkan kapasitas sekolah melalui peningkatan pengetahuan dan keterampilan yang diperoleh guru-guru dengan mengikuti kegiatan sharing for Indonesia.

2. SIPPKOM dapat meningkatkan kapasitas sekolah melalui peningkatan pengetahuan guru dan orangtua melalui penggunaan fitur layanan konsultasi yang disediakan.

3. Permasalahan yang dihadapi guru dan siswa terkait dengan pengembangan media pembelajaran di luar kelas, pemahaman dan kemampuan melaksanakan layanan PAUD HI, kemampuan memanfaatkan IT untuk pembelajaran, penguasaan IT sejak dini, serta pembentukan sikap kreatif dan adaptif bagi para siswa teratasi melalui kegiatan sharing for Indonesia dalam bentuk sosialisasi, pelatihan dan pendampingan.

Saran yang dapat diberikan adalah 1). bagi kepala sekolah agar dapat turut serta memantau penggunaan SIPPKOM oleh guru, sehingga mengetahui interaksi yang terjadi di dalamnya baik antara guru, orangtua, maupun siswasiswinya dan manfaat dari hasil komunikasi dan interaksi tersebut pada aspek yang dikonsultasikan. 2). Bagi tim pelaksana abdimas, agar terus mengembangkan berbagai fitur dan layanan konsultasi yang mencakup berbagai keilmuan sehingga kebutuhan informasi masyarakat pada berbagai bidang dapat terpenuhi. 3). Kerjasama sudin pendidikan dapat ditingkatkan hingga ke dinas pendidikan provinsi sehingga daya jangkau dan sasaran pengguna dapat lebih banyak.

\section{UCAPAN TERIMA KASIH}

Ucapan terima kasih kami berikan kepada Direktorat Jenderal Pendidikan Tinggi Riset dan Teknologi atas bantuan pendanaan Program Penelitian Kebijakan Merdeka Belajar Kampus Merdeka dan Pengabdian kepada Masyarakat Berbasis Hasil Penelitian Perguruan Tinggi Swasta Tahun 2021, kepada mitra Suku Dinas Pendidikan Wilayah 1 dan 2 Jakarta Selatan, Suku Dinas Pendidikan Wilayah 1 dan 2 Jakarta Pusat, kepala sekolah, guru, dan orangtua dari lembaga TK, SD, SMP, SMA-SMK di wilayah Jakarta Selatan dan Jakarta Pusat, serta lembaga penelitian dan pengabdian masyarakat Universitas Al Azhar Indonesia.

\section{DAFTAR PUSTAKA}

Abdurohman, M., Kuspriyanto, Sutikno, S., \& Sasongko, A. (2010). PerancanganAturanTransformasiUmlSystemcDalamPerancangan Embedded System. Jurnal Ilmu Komputer Dan Informasi, 3(2), 91-97. Https://Doi.Org/10.21609/Jiki.V3i2

Kustiyahningsih, Y., Rosa, D. (2011). Pemrograman Basis Data Berbasis WEB Menggunakan PHP dan Mysql, Yogyakarta: Graha Ilmu. 